\title{
Integration and Visualization of Information into the Database when Compiling Electronic Digital Demographic Maps
}

\author{
Abdurakhmonov Sarvar, Allanazarov Olimjon, Mukhtorov Uzbekkhon,Mirjalalov Nuriddin, \\ Abdurakhmonov Zoirjon
}

\begin{abstract}
Today, works such as the creation of thematic maps and plans, their processing, the formation of databases, integration and visualization have been considered one of the main objectives of GAT technology. Collection of information in the creation of electronic demographic cards, the formation of database, in accordance with them is carried out on the basis ArcGis, MapInfo, Panorama, GeoDraw, GeoGraph, Atlas Gis, Win Gis, ArchInfo and other programs. Analysis was carried out to improve the accuracy of the data on the maps, as well as in the creation of maps to observe demographic processes and predict demographic processes. This article provides comments on the collection and use of modern methods of creating electronic maps, visualization, integration of spatial data, as well as-to create socio-economic maps.
\end{abstract}

Keywords: electronic map, visualization, integration, statistical information, cartographic product, multimedia, demography, population, cartographic source, plan.

\section{INTRODUCTION}

As human consciousness and thinking develop, its needs also continue to increase. We always hear in the media, it is not surprising that the XXI century is considered the information age, the age of technology and technology. It is natural for us to find our place in life if we are not in solidarity with the Times Now and are not able to learn and master the news in a timely manner. In recent years, tremendous research and research has been carried out in all sciences and fields and unprecedented results have been achieved. In particular, it is no secret that cartography and Geoinformatics are developing as a field of Science, Technology and production. The penetration of geographic information systems (GIS) into science has led to the development of the industry more rapidly pictures. [6].

Revised Manuscript Received on July 22, 2019

* Correspondence Author

Abdurakhmonov Sarvar, Senior Lecturer, Department of Geodesy in Geoinformatics, Tashkent Institute of Irrigation and Agricultural Mechanization Engineers, Uzbekistan

Allanazarov Olimjon, Doctor of Philosophy in Technical Sciences (Doctor of Philosophy), Tashkent State Technical University Named after Islam Karimov, Uzbekistan.

Mukhtorov Uzbekkhon, Senior Lecturer, Department of Geodesy in Geoinformatics, Tashkent Institute of Irrigation and Agricultural Mechanization Engineers, Uzbekistan.

Mirjalalov Nuriddin, Trainee Lecturer, Department of Geodesy in Geoinformatics, Tashkent Institute of Irrigation and Agricultural Mechanization Engineers, Uzbekistan.

Abdurakhmonov Zoirjon, Trainee Lecturer, Department of Geodesy in Geoinformatics, Tashkent Institute of Irrigation and Agricultural Mechanization Engineers, Uzbekistan.

\section{PURPOSE AND OBJECTIVES OF THE WORK}

Today, electronic digital maps of the 1:5000 scale of the regions belong to the GIS family of software tools (ArcGIS, QGIS, Mapinfo...) is formed in programs and is being used in production organizations. By summarizing these maps with demographic processes, an expanded database of all cities, towns and villages can be formed. With the introduction of innovative technologies, on the basis of new information in places, statistical information belonging to the population is received online from on-site organizations and itegrasization with the base of geomatics makes it possible to constantly monitor the dynamics of the population in our republic.

\section{THE MAIN PART}

Integration is a very broad concept of meaning. To date, people have a good understanding of the essence of the integration process, it is necessary. What is integration? "Integration "-is derived from the Latin word" integration", which means" integral "is a whole, a whole; integration is a development in a interconnected way, it means to unite as a whole, to make it holistic. Integration is the process of combining different parts and elements into one whole. Integration processes can be in organized systems - in this case they increase the degree of integrity of the system and the degree of organization.

With the help of modern GPS receivers, it is required to carry out research work by specialists in the field with the aim of aggregating or updating territorial information. From carrying out the research work, the GPS receivers are loaded with an electronic digital map, which is created and shaped in the ArcGIS application.

The loaded electronic digital map GPS is activated in the receiver. GPS an order is issued to connect the receiver with satellites to bring it to a working state. When connecting with satellites, at least 4 channels are required to be filled, and the PDOP error in the connection should not exceed 5. In the territory of the Republic of Uzbekistan, it is possible to connect an average of 10 to 12 satellites. Possibility of satellite communication from 4 to 8 in the zones with high magnetic field and Foothill and foothills provides. In carrying out the research process as the creation of demographic electronic maps in places, the following information in the area will be examined: 


\section{INTEGRATION AND VISUALIZATION OF INFORMATION INTO THE DATABASE WHEN COMPILING ELECTRONIC DIGITAL DEMOGRAPHIC MAPS}

- Total number of population; women; men; children; disabled; nuronians; Nations; death (reduction); birth (increase); labor resources; employment of the population, such information is studied on the basis of reliable sources and entered into the receiver GPS. (Table 1)

Table 1:Population density data

\begin{tabular}{|l|l|l|l|l|l|}
\hline \multicolumn{7}{|c|}{$\begin{array}{l}\text { Population density 1kv.km.ga the correct } \\
\text { number of inhabitants }\end{array}$} & $\mathbf{0 1 4}$ & $\mathbf{0 1 5}$ & $\mathbf{0 1 6}$ & $\mathbf{0 1 7}$ & $\mathbf{0 1 8}$ \\
\hline & 01,3 & 03,6 & 05,9 & 08,1 & 10,2 \\
\hline $\begin{array}{l}\text { Kashkadarya } \\
\text { region }\end{array}$ & 14,8 & 17,3 & 20 & 22,5 & 25,1 \\
\hline $\begin{array}{l}\text { Surkhandary } \\
\text { a } \\
\text { region }\end{array}$ & & & & & \\
\hline
\end{tabular}

The table was compiled by the author based on the data of the Statistics Department of UZR.

GPS before entering information into the receiver, the coordinate is obtained in the dotted layer due to the geographic location of the area. These collected information is entered into the table of the obtained coordinate attributable data. The information included in the database is aggregated to the server in an online manner for the implementation of integration with the software. A copy of the reserve for emergency situations is obtained automatically on the server with the collected data. Then the information to the memory drive of the working computer is automatically transmitted in the style. (Picture 1)

Picture.1. Structure of integration

An electronic digital map created in the ArcGIS program on the computer is loaded. The received data and the collected information are imported to the uploaded electronic digital map using the GPS receiver. Imported points are automatically linked to the territory according to the geographic location according to the system of State coordinates spatial in style. Information complements the table of attributable data. On the basis of information in the table of attributable data, conditional signs are formed, relying on all indicators. Conditional signs are visualized in the form of several diagrams.

It is known that initially GAT technologies were used for the purpose of exact visualization. What do we understand when we say a visual look at the development of demographic process maps and what is their implementation into life? maps can be viewed visually (by eye), or by computer, digitally, from the human side. When visually compared from the human side, different differences or similarities can be found based on human intuition [1]. And now there are opportunities for visualization in various forms by GAT technologies, which are described not only in the form of a map, but also in the form of tables, diagrams and other forms of interaction with the user.
In order for GAT technologies to create a virtual Real system, visual communication is of great importance, in which all Gat technology images are used. Visual communication is divided into orientation and navigation, selection, management and analysis functions. If the user is within the $3 \mathrm{D}$ environment, these functions should be reflected in the $3 \mathrm{D}$ environment as much as possible. This can be done by using the virtual world itself [57; 123-b. [ ... ].

In this regard, we can see that there are demonstrations of the information-rich work of visualization, the creation of new structures for structured and unstructured data. For example, Examples include Tree Maps, Cone Trees, Perspective Walls, Star Field displays, Hyperpolic trees, DOITrees, Space Trees, and others [78; 2-b.[ ...].

In this regard, due to the characteristics of the maps in the process of visualization, their functions in connection with space processing are a graphical database or a spatial data source graph in the form of a cartographic work. An experienced specialist in the production of visual products requires the need to build graphics and spatial databases 
with high accuracy in order to activate visualization.

Visualization has been evolving in every area to date. Creating a visual image based on modern GAT technologies can be the foundation for many achievements in the creation of population maps, like every industry. To do this, a modern visual equivalent is created by using visualization. Data sources are concerned with information graphics, information visualization, research data analysis and statistical graphs. This in turn encourages information to be sought in visual perception while enhancing the excellence of self-research work.

We found that spatial demographic data has the following advantages in layered organization:

- ability to change the visibility of layers in the visualization of the demographic map;

- possibility to change the layout of layers in the visualization of the demographic map;

- possibility to independently adjust the visualization parameters of each layer available in the drawing of maps;
- possibility of Independent de spatial analysis on the layers of geographic maps;

- the possibility of forming maps from different levels of detail and resultant layers based on software tools is an advantage.

It requires visualization of spatial demographic data in the form of a map and the emergence of features of 3D-dimensional visualization.

In the visualization of spatial data on the go, the chief print sip is the application of layered organization of spatial data. In this, one type of data is grouped into layers. Here it is possible to understand that one type of data has a semantics similar to DE, or objects having the same size or topological structure [2].

Following the formation of the link by implementing theisgis software and reception receiver intergation, the next research will come to the database in the form of automatic information. It is carried out by visualizing the database on the basis of new information. (Picture 2)

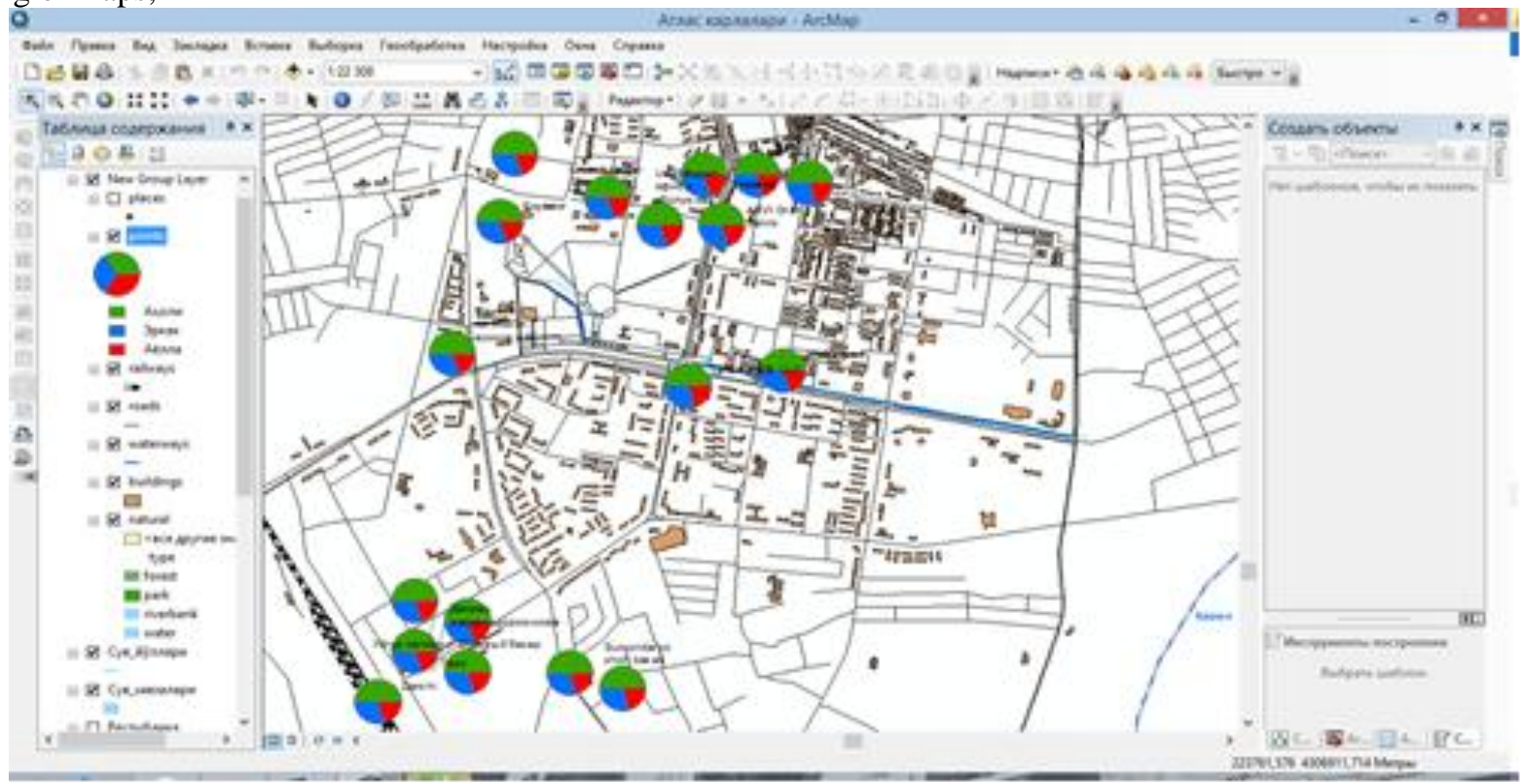

Picture.2. Receiving and online updating information from regions

We can see the predominance of GAT technologies, along with their wide coverage, as well as their capabilities in the expression of spatial data on the basis of cartographic images.

As a result, it turned out that the use of existing paper maps as a basis in the creation of digital and electronic maps of some regions did not give the expected result.

Therefore, in the first place it is required to create a cartographic basis. In order to reflect the processes on the maps, we used remote sensing materials to create a cartographic basis. In the creation of a new cartographic basis, initially images from the landsat space apparatus were used. In the sequence of methods and technology of drawing up electronic and digital maps, the formation of new printsipial stages in the process of preparing the original maps and obtaining copies from them is directly related to software belonging to the family of geographic information systems.

The technology of creating electronic demographic maps has been developed. (Picture 3)

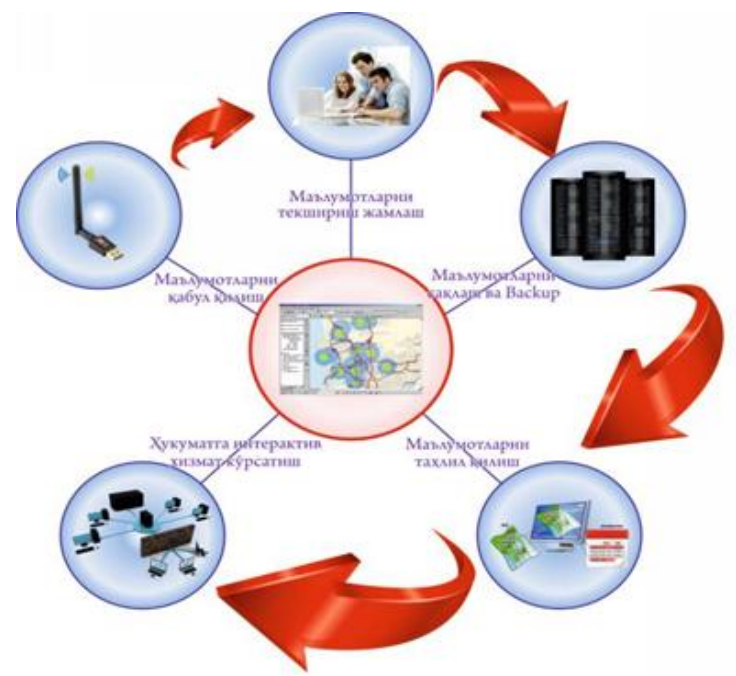

Picture.3. Technology of creating electronic maps

Published By:

Blue Eyes Intelligence Engineering \& Sciences Publication

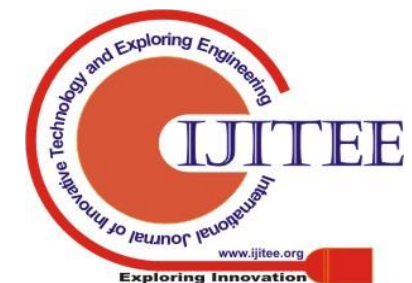




\section{INTEGRATION AND VISUALIZATION OF INFORMATION INTO THE DATABASE WHEN COMPILING ELECTRONIC DIGITAL DEMOGRAPHIC MAPS}

In the creation of maps based on the technology of creating electronic demographic maps, paper and electron digital maps and related tables, text and other data related to the subject that is initially needed to the computer memory in the data input system are collected.

Secondly, in the data verification system, all the collected data are checked and systematized.

For example, in a data storage system, the above systematized information is stored on a central database server in files based on a certain order.

In the next Fourth analysis system, all the collected information is analyzed on the subject and transmitted to the requested organizations and other government bodies for interactive service.

At the fifth stage, interactive service organizations provide information to the requested location.

The final stage, that is, in the analytical and statistical analysis of dynamic changes, performs forecasting actions based on the data collected by the researcher in carrying out forecasting work on various topics. Develops their maps if necessary

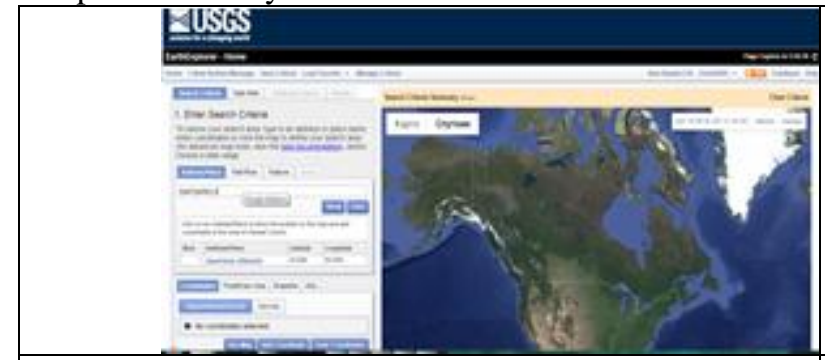

Picture.4. Earth Explorer download space pictures via geoportal

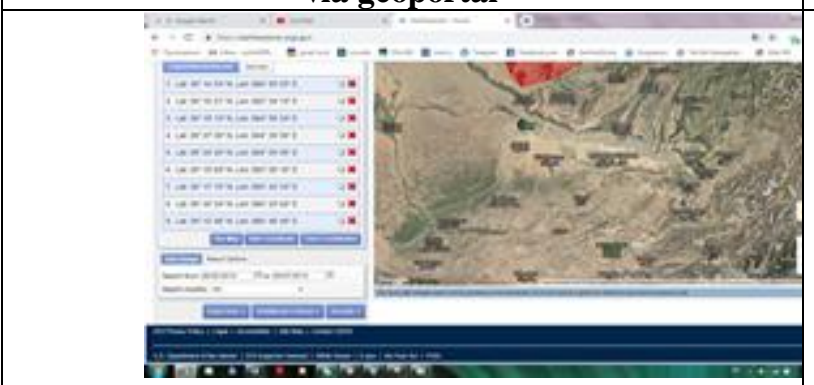

Picture.6. Selection description of the time of the selected area

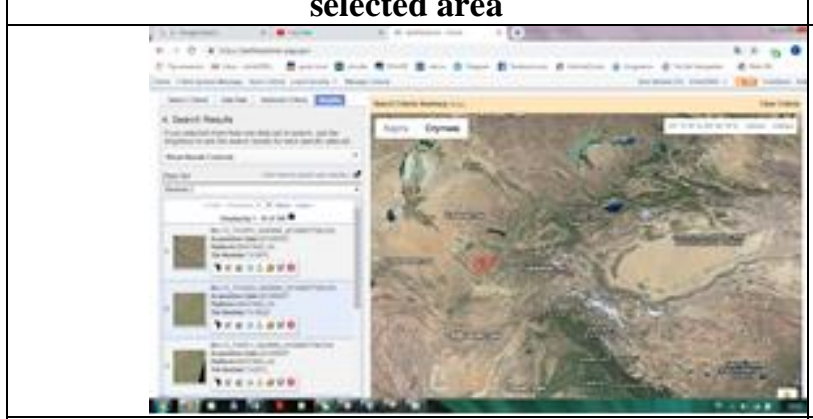

Picture.8. Regions in the space image
We can see that remote sensing techniques give good opportunities when it comes to supporting remote sensing techniques, reviewing analytical research, monitoring and analyzing processes, as well as creating maps based on the accumulated results.

In order to increase the accuracy of the data on the maps, as well as in the creation of maps for the observation of demographic processes and forecasting of demographic processes, analysis was carried out. To do this, space photos via geoportal Earth Explorer was downloaded and exported ArcGIS software, an NDVI analysis was carried out in the following sequence.

- That photos were downloaded through geoportal Space via Earth Explorer (Picture 4).

(Picture 5);

- Initially https://earthexplorer.usgs.gov / opens password;

- Check in to the geoportal, get a Login and coordinate.

-The required area is selected or searched by

Picture.5. https://earthexplorer.usgs.gov window

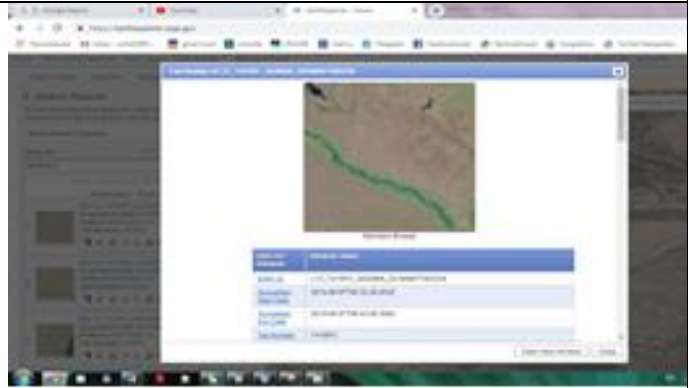

Picture.7. Entering the indicators of the space photo

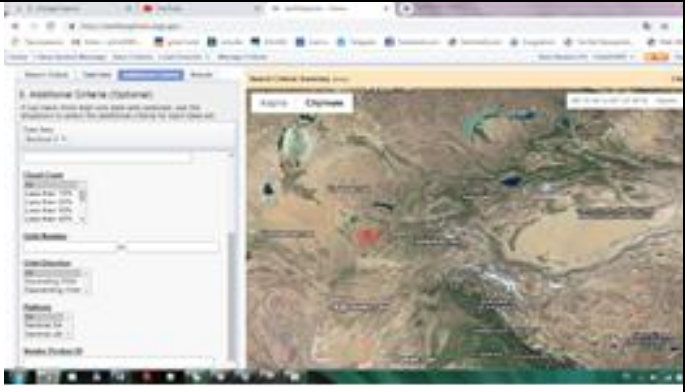

Picture.9. Adding more information to metadata 


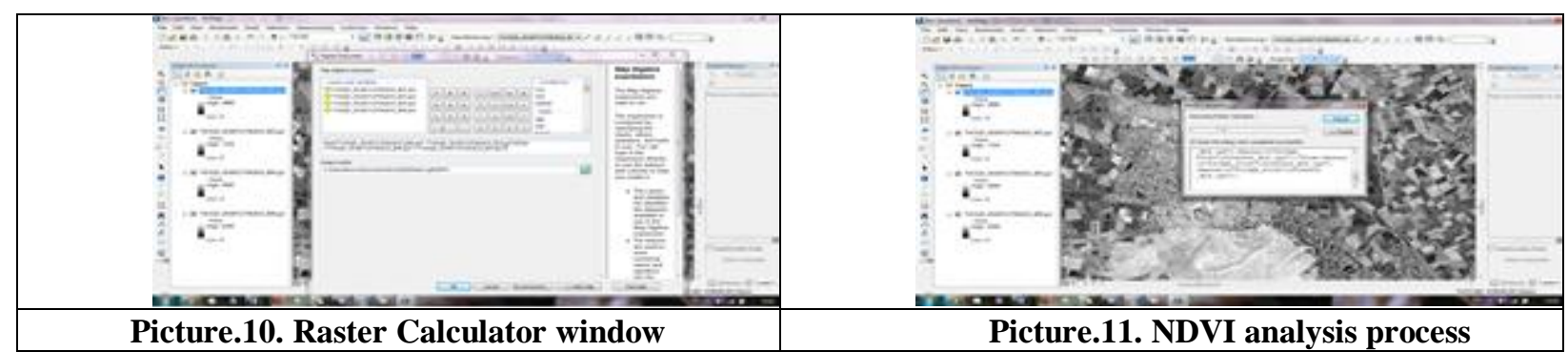

The period specified in the measure, in which the image of the selected area is indicated, at what time it is necessary, is given (Picture 6).

After determining the required zone, the space photos system in the base is selected.

The next stage will be a series of additional cretices. In this line, the pictures are covered with clouds, the number of the orbit, the title of the photo and other indicators are entered (Picture 7).

Then the result will be given a search, and the images of the area will be displayed (Picture 8).

More information about the space photo can be obtained by Metadata (Picture 9).

The resulting images are exported to ArcGIS software and analysis work can be carried out.

We will examine the aspects of attachment to demographic processes in the NDVI analysis. When performing the NDVI analysis, we will need a red and infrared spectrum of the image. In it, through the instrument panel (toolbox), a Map Al paneling is inserted into the panel of the spatial analysis device (Spatial Analyst tool) and then into the Raster calculator. formula

$\mathrm{NDVI}=(\mathrm{IQ}-\mathrm{Q}) /(\mathrm{IQ}+\mathrm{Q})$ is calculated by the

In this way, Spectrum IQ-infrared of the image

Q-red spectrum of the image

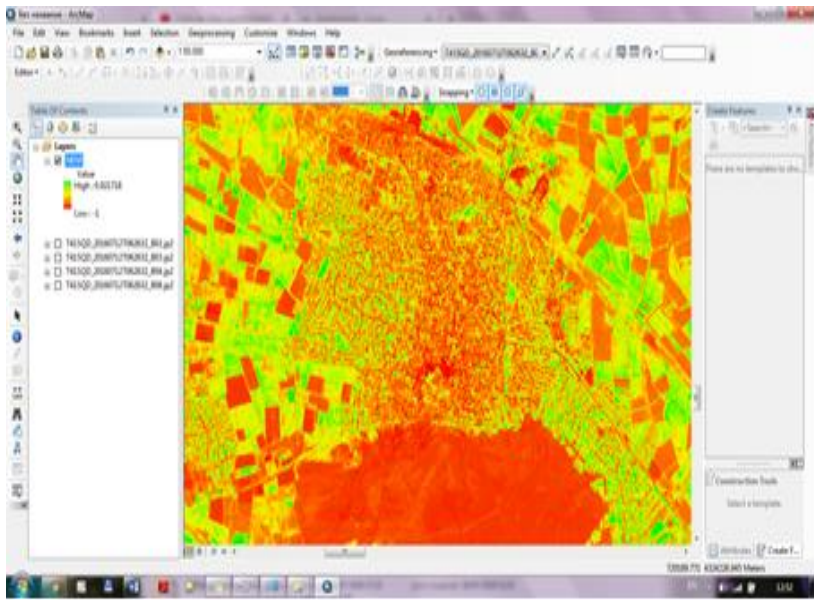

Picture.12. NDVI analysis result

Usually the value of the results obtained by analysis varies from 1.0 to -1.0 . The corresponding values of population punks were observed to be in the range of approximately from 0.6 to 0.22 .

In the processing of remote sensing materials, the obtained photos transformational work initially tied to the trapezium in the form of a photo frame [9; 106-110-b.] were completed and separate vector layers of general geographic elements were formed. Topographic maps were prepared as a basis in the compilation of the first demographic maps of the southern region. Then work was carried out to check the quality and topology of the electronic database of the map.

The next stage is the vector layers *.sxf. ArcGIS Files extension *. converted to shp format. ArcGIS, general geography, geography, population punks, roads, borders, relays, industrial and social objects were formed in a separate layer and files.

The result of the above work on the new cartographic basis created in the program, that is, statistical data collected in the central database using the method of geolocation, were interrelated. Then, the first map, called the demographic processes of the southern region, was drawn up while using cartographic imaging methods (Picture 13).

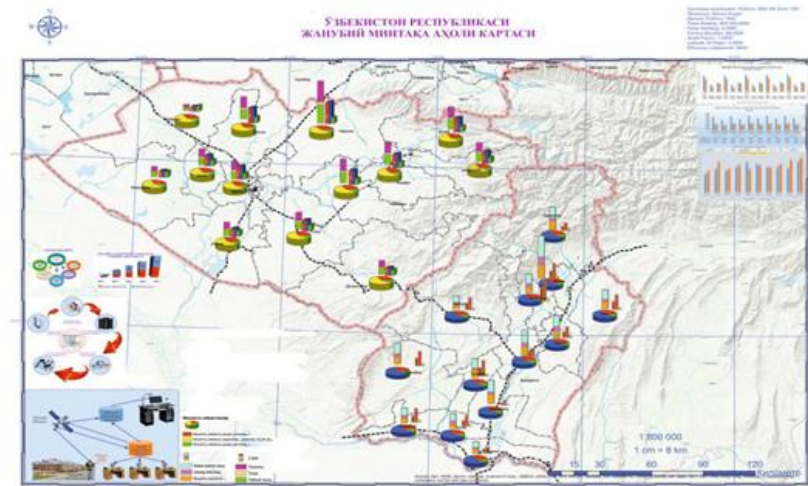

Picture.13. Southern region population map

Thus, in the creation of electronic digital maps and visualization of demographic processes, it was made possible to develop a structure of direct integration of information into the database of geometries, as well as to carry out automatic analytical work, to process remote sensing materials and to express spatial data on the basis of a cartographic image due to all possibilities.

\section{CONCLUSION}

Analysis of the theoretical framework for cartelizing demographic processes using Geoinformation Technologies showed that the interconnection of GATS and maps with each other is constantly replenishing each other. To describe processes or objects in nature and society, traditionally literary, statistical, cartographic, Aero and cosmic materials are used. Modern methods of processing computer equipment and data in the collection and processing of data on objects, processes and phenomena, a new approach using GAT, will serve as a perspective. So, in most cases, it was considered that Geoinformatics and cartography should focus on their interdependence, and generally a problem of two sides, on the one hand, the Geoinformation supply of cartography, on the other hand, the cartographic supply of

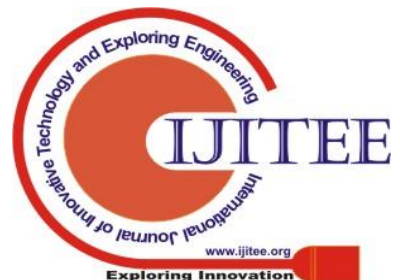


Geoinformatics, on the other hand, the emergence of cartography and Geoinformatics in terms of interconnection.

\section{REFERENCES}

[1]. I.Musaev. A'.Mukhtorov. Ergashov M. Geoaborot systems and technologies. Tashkent 2015.59 b.

[2]. RV. Gavin, N.G. Markov. Geoinformation systems. Tomsk 2008. It's 69b.

[3]. Safarov E.No, it's not., Prenov Sh.M. and et al. Cartography and geovizualization. Tashkent-2015 $123 \mathrm{~b}$.

[4]. Huisman O, Ralf A. de By, "Principles of Geographic Information Systems". The Netherlands-2009 year. [453 p.]

[5]. Popelka S, Brychtoava A,"Olomouc - possibilities of geovisualization of the historicality". Czech Republic-2000 year. [267p.]

[6]. Jeffrey H, Stuart K. map, James A. Landay, "a toolkit for interactive information visualization". USA-2006 year 2p., 267p.

[7]. Kang-Tsung dust. Introduction to Geographic Information Systems. Worth edition. - McGraw Hill Education (India) 2008. - 450 p.

[8]. Abdurakhmanov S. N. Development of data on the creation of maps of demographic processes in the system of geographic information technology / / XXI International scientific and practical conference Advances in Science and Technology. RUSSIA in June 2019.

[9]. Abdurakhmonov S.N. Geoinformatic Systems and Technologies (GAT) and Information on the Use of GPS Accessories in Integrated Demographic Process // International Journal of Multidisciplinary Research and Publications ISSN: 2581-6187. 2019 y.

[10]. Akbarova N. Written dissertation for Master's academic degree [10 b.].

[11]. Raklov V.P., Safarov E.No, it's not., Abdurahimov X.A. Geographic Information Systems. - T.: Science, 2007. - 140 P.

[12]. Shokirov Sh., I.Musaev. Remote sensing T-2015. 195 p.

[13].Tojiyeva.Z. O`zbekiston aholisi: o`sishi va joydanishi. Monografiya. - T: Fan texnologiya, 2010.- 113b

[14]. ttp://www.ESRI.com

[15]. ttp://gis-lab.info

[16]. ttp://www.geospatialworld.net

[17]. ttp://www.gisig.it/best-gis/Guides/main.tm

[18]. ttp://www.gisinfo.ru

[19]. ttp:// ttp:lex.uz

[20]. ttp://www.dataplus.ru/

[21]. ttp://www.cadacademy.ru/

[22]. ttp://www.gis.nnov.ru

[23]. ttp://www.sasgis.org

[24]. ttp://www.stat.uz. 